\title{
Recombinant Vaccinia-Mgp100 Vaccine
}

National Cancer Institute

\section{Source}

National Cancer Institute. Recombinant Vaccinia-Mgp100 Vaccine. NCI Thesaurus. Code C51978.

A recombinant vaccinia virus encoding a modified peptide of the gp100 melanomamelanocyte antigen with potential use in cancer immunotherapy. gp100 human antigen is a wild type self-antigen expressed by melanocytes, pigmented retinal cells and most melanomas. This recombinant vaccinia Mgp100 encodes a fragment epitope of gp100 bearing 2 amino acids substitution; T->M at position 210 and $288 \mathrm{~A}->\mathrm{V}$ at position 210. This modification may stimulate tumor infiltrating lymphocytes (TIL) more efficiently. 